[Zepke, N. (2003). Adult Learning, Tertiary Education Policy in New Zealand and the Future. New Zealand Annual Review of Education, 12, 5-20]

\section{Adult Learning, Tertiary Education Policy in New Zealand and the Future}

\section{NICK ZEPKE}

\section{Abstract:}

This article traces ideas about adult learning from Unesco's Hamburg Declaration (1997) to the Labour government's Tertiary Education Strategy (2002) and speculates how these ideas might fare over the next five years in a policy context dominated by "third way" politics. It is divided into three sections. In the first, the Hamburg Declaration's Agenda for the Future is discussed in the broader framework of thinking about adult learning. In the second, the themes from the Agenda for the Future are used to analyse the emerging strategies for tertiary education in New Zealand. In the final section it is suggested that the "third way" future envisioned by the Strategy is beset with economic, social and cultural tensions.

ince its election in 1999, the Labour-Alliance coalition government has been designing a future for adult learning in New Zealand. The fruits of this work were released in May 2002 as a strategic action plan in a booklet titled Tertiary Education Strategy 2002-2007. This article aims to explore some of the influences on the design of this strategic action plan. In particular it focuses on two visionary Unesco documents about a future direction for adult learning, The Hamburg Declaration (1997) and its Agenda for the Future. These were acknowledged in Labour Party election documents in 1999 as influential in shaping its education policy agenda. The paper also places both adult learning and tertiary education policy into a wider context - the discourse of "the third way". It suggests that any future shaped by "third way" politics could be beset by economic, social and cultural tensions.

This is not an uncomplicated project. Adult learning occupies a multi-faceted intellectual terrain that is not easily captured by a single meaning. To avoid bogging down in contested meanings of adult
6 Nick Zepke

learning, the Hamburg Declaration (1997) and its Agenda for the Future serves as a widely accepted statement of mainstream adult learning principles. Conveniently it offers a broad definition of adult learning which

... denotes the entire body of ongoing learning processes, formal or otherwise, whereby people regarded as adults by the society to which they belong develop their abilities, enrich their knowledge, and improve their technical or professional qualifications or turn them into a new direction to meet their own needs and those of their society. (p. 1)

In addition to espousing personal and social development approaches to learning, it is a political document that connects the world of learning with the world of educational policy pursued by active governments.

In New Zealand, adult learning largely takes place within the tertiary education sector. But policy making for this sector is not a simple matter.. It is forged within a broader policy orientation called the "third way". With the establishment of a Tertiary Education Advisory Commission (TEAC) early in 2000, the Labour-Alliance government signalled a strategic direction for tertiary education that would enable New Zealand "to become a world-leading knowledge society" (2000, p. 32). Over four reports, TEAC produced a strategic direction strongly influenced by "third way politics" (Codd, 2002). The "third way" tries to avoid the extremes of both neo-liberalism and the welfare state by emphasizing "social inclusion, pluralism, and democratic involvement within an active civil society that supports a market economy" (Codd, 2002 , p. 32). But the very concept of the "third way" is problematic, as the title of a recent book - The Third Way and Its Critics - by one of its prophets suggests (Giddens, 2000). In particular, it is doubtful that the tensions inherent in an active government supporting both social cohesion and a free market can be managed easily into the future. This puts into doubt the future of both the "third way" and the ideas in the Agenda for the Future.

Any discussion of the future is even more problematic. The future has not yet happened, so giving this paper a "future focus" is far from straightforward. All that can be said with certainty is that a future focus enables constructive thinking about present and future (Bell, 1998). Toffler (1976) and Amara (1991) have theorized three ways of using a future focus. The first they call the art of the possible. The researcher calls on intuition and creativity to form images of alternative futures. The 
second they call the science of the probable. This is forecasting proper. Trends from the past and present are analysed as to their possible effects and then projected into the future. The third aspect Toffler and Amara call the politics of the preferable. Here the researcher develops preferred policy ideas based on the values, assumptions and preferences of specific groups of people. It provides political contexts within which planning can take place.

This article is divided into three sections. In the first, the Hamburg Declaration's Agenda for the Future is discussed in the broader framework of thinking about adult learning. In the second section, the themes from the Agenda for the Future are used to analyse the emerging strategies for tertiary education in New Zealand. In the final section the politics of the preferable approach to the future is used to suggest that the "third way" future envisioned in the Strategy booklet is beset with economic, social and cultural tensions.

\section{Adult Learning and the "Agenda for the Future"}

The intellectual terrain of adult learning is complex, as various attempts to map the field show (Elias \& Merriam, 1995; Pratt, 1999; Tisdell \& Taylor, 2001; Finger \& Asun, 2001). Elias and Merriam identify six different philosophical traditions in adult education. They label these liberal, progressive, behaviourist, humanist, radical and analytic. Of these, the liberal and analytic traditions, with their emphasis on transmission of logically organized bodies of knowledge by an authoritative teacher, have faded in importance. The others continue to be influential. Progressives argue a pragmatic philosophy stressing an experiential, problem solving approach to learning. Behaviourism emphasises environment in shaping desired behaviour. It favours systematic and competency-based approaches to learning, particularly for induction into the work force. The humanist tradition offers a very positive view of human nature with each individual having virtually unlimited potential in pursuing self-directed personal growth. Radical adult educators stress the role of education as a means of bringing about major social change. Learning should equip people to combat social, political and economic oppression.

Elias and Merriam (1995) acknowledge that these philosophical traditions are not practised in isolation from each other. "While much of adult education practice is behaviorist, much of the rhetoric is humanist....(R)adical writers...are providing us with tools to examine our practice and theory, and with new insights into understanding why things are the way they are" (p. 237). The complexity of the terrain is further highlighted by the advent of post-modern perspectives (Zepke \& Leach, 2002). Three aspects of post-modern thinking seem particularly pertinent. The first contends that society is not perfectible in a universal way. Struggles between opposing ideas are unlikely to be resolved. The second aspect of post-modernism concerns the uncertain status of knowledge. Knowledge is seen as provisional, relevant to its own context but not beyond this. It has, therefore, a multiplicity of meanings and undergoes constant re-interpretation in a continuous debate between competing claims. The third aspect follows from this. Teachers and learners must be ready to grapple with difficulty, uncertainty and error.

In this context of differences about the meanings of adult learning, it is not easy for governments to make sensible policy for it. An intellectual framework is needed to guide policy makers. Since 1971, Unesco has attempted to provide such a framework. A report, Learning To Be: The World of Education Today and Tomorrow (1972), was a visionary document that did not specify structures and policies in detail, but developed an overarching conceptual framework for individual countries to develop their own policies. Central to this framework was the concept of lifelong learning. According to Butler (cited in Candy, Crebert \& O’Leary, 1994, p. 17),

...what was revolutionary about Learning To Be was the idea that education should be a lifelong process for all adults and that governments should use this as the basis upon which they design their whole education systems. Education for adults should no longer be merely "tacked on" to a system designed for children and young people.

The concept of lifelong learning has remained a centre-piece in Unesco's work in adult education. Certainly it appears repeatedly in the Hamburg Declaration and the Agenda for the Future. For example, the Hamburg Declaration (1997, p. 1) states, "Learning throughout life implies a rethinking of content to reflect such factors as age, gender, equality, disability, language, culture and economic disparities." The Agenda for the Future $(1997$, p. 2) recognizes that adult learning "has become an imperative at the workplace, in the home and in the community, as men and women struggle to create new realities at every stage of life." It is these new realities that give rise to the Agenda for the Future. 
Profound changes are taking place both globally and locally. They can be seen in a globalization of economic systems, in the rapid development of science and technology, in the age structure and mobility of populations, and in the emergence of information-based and knowledge-based society. The world is also experiencing major changes in patterns of work and unemployment, a growing ecological crisis, and tensions between social groups based on culture, ethnicity, gender roles, religion and income. (p. 1)

These new realities affect adult education profoundly. Policy makers and educators have difficulties coping with such major changes, both conceptually and economically. What is required is a policy agenda that addresses these difficulties. The Agenda for the Future offers policy suggestions under ten thematic headings. These are not separated rigorously in the document and overlap in places, so for the purposes of this paper the ten have been compressed into the following six.

\section{Democracy}

The Agenda calls for a new partnership between the state and civil society to recreate democracy. This partnership is needed to facilitate greater equality. Specifically mentioned is the need for greater say by poor people, women and minority ethnic groups and cultures. Adult learning is a key instrument in achieving this goal. Specific policy suggestions include the creation of democratic learning communities, the elimination of discrimination based on gender, race, language, religion, national or ethnic origin, disability "or any other form of discrimination" (p.2). Some suggestions about specific curriculum areas are included, for example: developing understanding of gender relations; offering linguistic and culturally appropriate programmes; and developing skills in non-violent conflict resolution.

\section{Equity and difference}

The right to education is seen as a universal right. However, the rights to education of many are severely restricted. This could mean their exclusion from formal power structures and decision-making processes. Groups such as women, the aged, migrants, disabled, prisoners and ethnic minorities are often excluded. Policies should be inviting to encourage such groups into formal and non-formal settings to meet their diverse learning needs. Suggested curricula ranged from consciousness raising about differences, to teaching about the effects of globalization and the implications for learning of collective ways of life.

\section{Literacy and basic education}

The Agenda emphasises strongly the importance of literacy and basic education. It must be relevant to learners' social-economic and cultural contexts. It is seen as a necessary "gateway to fuller participation in social, cultural, political and economic life" (p. 5). Policy suggestions include linking literacy to social, cultural and economic development aspirations, building links with traditional and minority knowledges and cultures, improving the training of adult literacy educators and publishing texts that directly reflect the knowledge needs of local communities. Curriculum suggestions include broadening definitions of literacy so that socioeconomic as well as cultural interests are acknowledged, and adopting learner-centred strategies.

\section{The changing world of work}

Globalization and new technologies have a powerful effect on all facets of adults' individual and collective lives. The Agenda acknowledges that economic changes require increased competencies in sometimes-new skill areas as well as the capacity to adapt to the ever-changing requirements of working life. Policies advocated include creating partnerships between employers and employees; offering work-related adult education to provide specific competencies needed for entry into the labour market and occupational mobility and the introduction of active work-place learning. Specific curriculum ideas include courses in entrepreneurship, work-place literacy and the development of awareness and understanding of the economic world.

\section{Environmental sustainability}

Learning how to care for the environment involves controlling pollution, preventing soil erosion and prudently managing natural resources. Environmental health directly impacts on human health, which in turn has implications for population development and the availability of food. The Agenda suggests policy developments in areas such as "education on family issues, reproductive life cycle and population issues such as ageing, migration, urbanization, and intergenerational and family relations" (p. 9). Curriculum suggestions include programmes based on ecologically and socially sustainable development, reproductive and sexual health and health-related courses dealing with disease treatment and prevention, nutrition, sanitation and mental health. 


\section{Improving the quality of adult learning}

The Agenda for the Future recognizes the need to improve both access to, and the quality of, adult learning. The use of mass media and new technologies to achieve these ends is underlined. Policy suggestions include: collaboration and partnerships between agencies, providing needs based learning, offering professional development opportunities to adult educators, researching adult learning, improving the financing of adult learning, and strengthening libraries and cultural institutions. Programme suggestions include training in new technologies and the media, developing distance programmes, recognizing experiential and prior learning, and observing special days such as International Woman's Day, International Literacy Day and Adult Learners' Week.

\section{The Tertiary Education Strategy 2002-2007}

The Hamburg Declaration and its Agenda for the Future capture how the four primary philosophical traditions of adult learning influence policy ideas. References to lifelong and experiential learning incorporate ideas from Progressivism. Humanism is very well represented in its focus on inclusiveness and catering for difference. Radical adult learning philosophies are present in the thrust for equity and environmental sustainability. Behaviourism is evident in the recognition that a globalized world requires new competencies for the international labour market. But Unesco documents are deliberately supranational - policy ideas for national jurisdictions to adapt to their own requirements. In order to speculate about future possibilities for adult learning in New Zealand it is important to examine policies and strategies developed for New Zealand.

In its policy statement for the 1999 election the New Zealand Labour Party stated:

The landmark Declaration on Adult Learning, issued by the 5th International Conference on Adult Education in Hamburg July 1997, calls for a renewed vision of education in which learning becomes truly lifelong.

Labour's education policy is built on a recognition of the crucial role of education in relation to social investment, lifelong learning and nation building. (Labour Party, 1999, p. 2)

The Labour-Alliance government's Tertiary Education Advisory Commission (TEAC) provided a blueprint for an integrated, inclusive, innovative tertiary education system, steered from the centre and leading to a knowledge society. TEAC's work has now finished and its ideas have been translated into an action plan.

In May 2002, the Ministry of Education published the government's Tertiary Education Strategy 2002-2007. In his foreword, the Minister for Tertiary Education writes, "the Strategy is one for 'tertiary education', and by that I mean all of the learning that takes place in the field of post- school education and training" (p. 4). True to his word, the strategy encompasses formal and non-formal learning activities. Tertiary Education is as much about ACE (Adult and Community Education) Learning Centres and Networks, workplace learning and foundation education as it is about universities, research institutes and doctoral studies. "It is as much about relevance as it is about excellence" (p. 4). The strategies are expected to increase relevance and integration of the system by aligning closely with national goals, linking with business and the wider global community and developing partnerships with Maori. They are designed also to increase responsiveness to learners and co-operation within the sector. They are expected to be future focused and lead to a culture of optimism and creativity.

The government has chosen six strategies to meet these expectations.

- The first strategy seeks to strengthen the system's capability and quality so that tertiary education can contribute to national goals. A mixed bag of objectives supports the strategy. These range from improved leadership and a coherent qualification system through greater collaboration with research and creative industries to increased differentiation and specialization of institutions, better teaching and learning and sustained growth of export education.

- Strategy two seeks to contribute to the achievement of Maori development aspirations. The strategy supports three goals for Maori educational advancement. These are: to live as Maori, to actively participate as citizens of the world and to enjoy a high standard of living. A high degree of self-determination for Maori underpins the strategy.

- The third strategy expects to raise foundation skills so that people can participate in the knowledge society. "The demands of our contemporary world require learning to be lifelong. Foundation skills are those skills that underpin the ability to learn and to keep learning" (Tertiary Education Strategy, 2002, p. 36). Foundation skill pathways, improved quality, best practice teaching and improved 
staircasing will help achieve the strategy.

- Strategy four seeks to develop the skills New Zealanders need for a knowledge society. The strategy envisages adults gaining skills for active citizenship, high level generic skills as well as specialist skills and making informed career choices. It expects institutions to provide for equity of access and to meet the self-identified skill needs of industry.

- The fifth strategy envisages education for Pacific Peoples' development and success. As a significant and rapidly growing population, Pacific Peoples' capability needs and skills development will be given special attention.

- Strategy six seeks to strengthen research, knowledge creation and uptake for the knowledge society. "This strategy recognises that research and innovation are key drivers of modern economies, and also that the broader application of new knowledge will enable the achievement of social, environmental and infrastructural goals" (Tertiary Education Strategy, 2002, p. 16). Objectives for this strategy focus on developing research capacity both in New Zealand and through fostering global connectedness. The strategy also underlines support for research that connects to national goals, for developing new researchers, particularly Maori, and improved application of research knowledge.

Even this brief summary of the government's intentions leaves little doubt that the content of the Agenda for the Future finds national expression in the Strategy. Most obviously both documents are very keen to improve access to, and equity in, all levels of adult education for minorities. Indigenous people, ethnic minorities and women are picked for special attention in the Agenda. Although women are not heavily featured in the Strategy, New Zealand's indigenous people, Maori, and the ethnic minority Pacific People, are. Strategy emphasises capacity building for all minority groups. Their emphasis on foundation skills reflects the Agenda's concern for literacy. Moreover, in relation to Maori, the Strategy echoes the Agenda in valuing difference, as Maori are given considerable space to develop in a self-determining way. Skill development, beyond literacy skills, also features in both documents. Whereas these are couched in general terms in the Agenda as work, media and healthy living skills, for example, Strategy is more concerned with specific generic intellectual skills and specialist technical abilities. In a more obscure way the Agenda's major interest in education for environmental sustainability has a small, silent role in the Strategy as one of the national goals to be reflected in tertiary education policy.

Both documents are explicitly future focused. The Agenda expresses its future as goals to be achieved. The Strategy attempts to capture the effects of the strategies in scenarios of assumed futures. Despite this difference, their general approach to the future is not dissimilar. This is not surprising as both are essentially political documents. Of the three possible approaches to the future theorized by Toffler (1976) and Amara (1991), both documents adopt the politics of the preferable approach. Very little intuition or creative impulses are evident and neither can it be said that the documents take a rigorous forecasting approach. Both proffer policy ideas derived from the strongly held assumptions of political élites to construct a certain kind of future vision.

But there are differences also. The Agenda focuses on people, Strategy on systems. Strategy sees tertiary education as separate from compulsory education, an add-on and development. The Agenda sees education as a wholistic process without boundaries for adults who need to be learners in the compulsory sector. The use of the concept of development is another difference. Strategy uses the term to signify economic, social, Maori, infrastructural development - systems development in short. For Agenda the emphasis is on the development of individuals and groups. The purpose of such development is to enable individuals and groups to build a better democracy: strengthening and protecting human rights, promoting a culture of peace, encouraging active citizenship, recognizing cultural diversity and promoting a new partnership between state and civil society. Strategy also supports these purposes, but places its faith for their achievement in system building and development.

The term "knowledge society" is largely absent from the Agenda but a feature of Strategy. This is significant, for it is in the notion "knowledge society" that a raft of economic imperatives is hidden. Strategy is transparent in calling for tertiary education to assist in an economic transformation. This requires New Zealand to diversify its economy, beyond relying on its natural resources such as animal and plant growth and spectacular landscapes, by gaining new competitive advantages that will avoid negative trading cycles and generate sustainable economic growth. The component to add value and maintain competitive advantage is information.

The major reason why the information revolution is so important to New Zealand is because the associated computer technologies and 
biotechnologies allow us ...to ensure the whole economy produces products that sell on image and performance rather than price competitiveness alone. (Tertiary Education Strategy, 2002, p. 11)

The term "knowledge society" is a handy short-hand describing skills needed to use new technologies in the transformed economy. This economic imperative drives many objectives in the Strategy. While the Agenda strives to achieve general wellbeing of adult learners, its view of economic transformation is not something learners must help the nation achieve, but something the nation should assist individuals to survive.

\section{A Future Focus for Adult Education in New Zealand to circa 2007}

This article suggests that The Hamburg Declaration and its Agenda for the Future are futures policy-orientated composites of various traditional and post-modern views of adult learning. Ideas in the Agenda are clearly visible in New Zealand's tertiary education Strategy. In particular, a shared concern to promote cultural diversity by strengthening minorities through education has been noted. This potentially raises tensions between culturally dominant groups wanting to preserve their dominance and aspiring minorities who wish to challenge it. However, the New Zealand approach to the future of tertiary education is also different. Whereas the Agenda has a social and individual development focus, with economic development a means to that end, Strategy has a systems development focus in which economic development as well as social development are ends in themselves. This will give rise to tensions in the management of economic and social development and individual and systems development. How these potential tensions are handled will affect the future of adult learning.

Why address these particular tensions, when many others could be constructed? A partial answer lies in how the future is theorized. It was argued that both the Agenda and the Strategy adopt a specific approach to the future - the politics of the preferable. This approach enables the construction of futures based on a particular kind of policy framework. The approach to the future taken in this paper also uses the politics of the preferable. The paper has identified "the third way" as currently the dominant political discourse in New Zealand. It provides the overarching policy framework to which the tertiary education Strategy has been shaped. But this discourse seems to walk a tightrope of competing policy intentions. Two of these seem foundational to adult learning within tertiary education. One sees an active state trying to balance social justice and the market. The other tries to balance diversity and social cohesion.

\section{Balancing social and economic imperatives}

In summarizing the main tenets of "third way" politics, Giddens (2001) highlights the tightrope balances to be achieved. There is an active state, but it cannot interfere with responsible capitalism. Rights and responsibilities are carefully balanced so that neither is privileged as in, say, social responses to crime. Egalitarianism and full employment are pursued vigorously, but current welfare provisions need reform and the state will practice fiscal probity and engineer flexible labour markets. Most importantly, perhaps, there is no vision as to how these balances are to be maintained. "The third way" is not a developed philosophy, but a pragmatic response to needs: "what counts is what works" (Giddens, 2001, p. 5). Critics do not give "the third way" much chance of succeeding in its tightrope walk. Indeed, Kelsey (2002) argues that the tightrope is a mirage; that "the third way" enables centre-left governments to build on rather than end the neo-liberal project. "The result is a more embedded form of neoliberalism that perpetuates the tensions which the government was elected to relieve (Kelsey, 2002, p. 50). She uses an instructive quote from Prime Minister Helen Clark to summarize her argument, a quote that also clarifies the place of education in "third way" politics:

You don't have a choice of whether you ride (the tiger of globalisation) or not, but you can't ride it if your citizens are not educated, your infrastructures are not good enough, you're not innovative enough, you're not using technology enough, and you haven't moved on and upward to a new economy. That's the challenge facing New Zealand and everyone else. (Clark cited in Kelsey, 2002, p. 59)

This examination of "third way" politics lowers the expectation that an even-handed balance between economic and social imperatives might be maintained into the future. The internal tensions within "the third way" look likely to be resolved in favour of the pragmatic pursuit of economic advantage, which will reappear as the driving force in adult learning. This would have serious implications for tertiary institutions and adult learners. The meanings given in the Strategy to the knowledge society, for example, will probably subtly change to knowledge economy. As a result, government "steerage" may be an 
increasingly used mechanism. It is not inconceivable that in the drive for economic success, public-private partnerships are mandated for previously public institutions like universities and polytechnics. While adult learning will continue to be seen as lifelong, qualifications that are publicly funded may be reduced to those that have job-related outcomes. Even the now chartered and profiled non-formal sector could develop a strong focus on developing measurable generic foundation skills to the neglect of traditional personal and community development. Most importantly, a single-minded pursuit of the knowledge economy could make the notion of critical democracy an ever-diminishing dream.

\section{Balancing cultural protectionism and diversity}

Clark's "tiger of globalisation" has cultural as well as economic implications for adult learning and tertiary education. Networked trade and communications open New Zealand to cultural influences as well as economic ones. These are homogeneous and diverse at the same time. Popular culture is popular globally via television and the Internet, countries adopt public policy frameworks from other countries, consumer products like McDonald hamburgers and Coca Cola are the same in New Zealand as elsewhere. However, as Edwards and Usher observe:

... whilst globalization has resulted in the spread of Western institutions across the globe, that very trend also produces a pressure for local autonomy and identity. Thus the integration of the globe reconfigures rather than supplants diversity. (1998, p. 162)

Seething beneath the seemingly uniform surface are many points of difference and contradiction. Benefits are shared unequally; some get poorer as others enrich themselves. Indigenous cultures resist the global blanket by asserting their own traditional religious, legal, political, economic and technological ways. The pressure from them is for diversity. But Giddens (2001) is aware of a backlash against diversity. Cultural protectionism is evident in the ideologies of political parties of the right. Reacting against globalisation and growing cultural diversity, such parties champion the heritage and identity of the dominant culture. They are not minor threats to the "third way", as the growth of such parties in countries like France, Austria, the Netherlands and New Zealand indicates. Opponents of cultural protectionism champion diversity and self-determination of minorities. Ranging from bio-diversity to cultural diversity, policies are designed to challenge dominant western discourses and eliminate traditional patterns of dominance, subordination and epistemological hegemony (Bishop \& Glynn, 1999).

Few New Zealanders are unaware of the growing tensions between those favouring diversity and those advocating cultural protection. The differing positions of the main opposition parties and many Maori, for example, on questions of Maori self-determination are now very clear. But so are opposing views on immigration, indeed on the very nature of New Zealand's national identity. Traditional adult learning thinking, the Hamburg Declaration and the Tertiary Education Strategy strongly champion diversity. So by 2007, adult learning in tertiary education could achieve its diversity aims. For example, the Strategy's vision for the participation of Maori may be achieved as "Maori communities ... increasingly engage with a tertiary education system that is more supportive of Te Ao Maori (the Maori world) and which is inclusive of tikanga Maori" (2002, p. 29). However, there are indicators that suggest this view of the future may be idealistic. Maori self-determination may come to oppose immigration. This could interfere with the economic transformation to which "third way" politics aspires and cause the government to cool on diversity. And the vagaries of the ballot box may throw the Labour government off its cultural tightrope in 2004 by forcing it out of office or compelling it to forge a coalition with parties favouring protection of European culture. Only one thing seems certain then - the future of diversity in adult learning policy is uncertain.

\section{End Note}

It is possible to abstract many futures of adult learning from documents like the Agenda and the Strategy. There are a number of reasons for choosing the ones recorded here. Some have to do with the dominant policy discourse currently ruling New Zealand. It is always instructive to explore some of the possible implications of this dominance. It is equally useful to identify credible discourses currently waiting to challenge the dominant one. Such explorations can lead to evaluating and possibly changing the present to achieve a desirable future. Other reasons have to do with debate and critique. The radical strand of adult learning seems potentially restricted under "the third way". By painting the future in a somewhat bleak light, debate about present policy might be encouraged and the critical dimension of adult learning might be preserved, whatever the future. 


\section{References}

Amara, R. (1991, July/August). Views on futures research methodology. Futures, 645-648.

Bell, W. (1998). Understanding the futures field. In D. Hicks and R. Slaughter (Eds), Futures education: World yearbook of education. London: Kogan Page.

Bishop, R., \& Glynn, T. (1999). Culture counts: Changing power relations in education. Palmerston North: Dunmore Press.

Candy, P., Crebert, G., \& O’Leary, J. (1994). Developing lifelong learners through undergraduate education. Canberra: Australian Government Publishing Service.

Codd, J. (2002). The Third Way for Tertiary Education Policy: TEAC and Beyond. New Zealand Annual Review of Education, 11, 31-57.

Edwards, R., \& Usher R. (1998). Moving experiences: Globalization, pedagogy and experientiallearning. Studies in Continuing Education, 20(2), 159-174.

Elias, J., \& Merriam, S. (1995). Philosophical Foundations of Adult Education (2nd ed.). Malabar, Florida: Krieger Publishing Company.

Ellis, J. (1997). Agenda for the Future. CONFINTEA V. $<$ www.unesco.org/education/uie/confintea/declaeng.htm $>$ Retrieved from the Web October 8, 2002.

Fauré, E. (1972). Learning to be: The world of education today and tomorrow. Report of the International Commission on the Development of Education. Paris: Unesco.

Finger, M., \& Asun, J. (2001). Adult education at the crossroads: Learning our way out. London: Zed Books.

Giddens, A. (Ed.) (2001). The global Third Way debate. Cambridge: Polity Press.

Giddens, A. (2000). The Third Way and its critics. Cambridge: Polity Press.

Kelsey, J. (2002). At the crossroads: Three essays. Wellington: Bridget Williams Books.

New Zealand Labour Party. (1999). Pathways and networks: Labour on adult education and community learning (mimeo).

Office of the Associate Minister of Education (Tertiary Education). (2002). Tertiary education strategy 2002/07. Wellington: Ministry of Education.
Pratt, D. (1999). Five perspectives on teaching in adult and higher education. Florida: Krieger Publishing Company.

Sussmuth, R. (1997). The Hamburg Declaration on adult learning. Fifth Unesco Conference on Adult Learning.

$<$ www.unesco.org/education/uie/confintea/declaeng.htm $>$ Retrieved from the Web October 8, 2002.

Tisdell, E., \& Taylor, E. (2001). Adult education philosophy informs practice. Adult Learning, 11(2), 6-10.

Toffler, A. (1978). Foreword. In M. Maruyama \& A. Harkins (Eds), Cultures of the future. The Hague: Mouton.

Tertiary Education Advisory Commission. (2000). Shaping a shared vision. Wellington: TEAC.

Zepke, N., \& Leach, L. (2002). Appropriate pedagogy and technology in a cross-cultural distance education context. Teaching in Higher Education, 7(3), 309-323.

\section{The author}

Nick Zepke is an Associate Professor in the College of Education at Massey University with research interests that focus on futures studies, the sociology of knowledge, assessment and the scholarship of teaching adults. His most recent publication is an edited book - From Reflection to Transformation: A Self-Help Book for Teachers, published in 2003 by Dunmore Press. 